dependent on age, and delayed surgery may result in psychosocial deterioration.

Etiology as a risk factor for medically refractory epilepsy, and a case for early surgical intervention are presented in a study of 2,200 patients, ages 16 and older, from La Salpetriere Hospital, Paris (Semah F, Picot M-C, Adam $\mathrm{C}$, et al. Is the underlying cause of epilepsy a major prognostic factor for recurrence? Neurology Nov 1998;51:1256-1262), and in an editorial (Engel J, Jr. Neurology Nov 1998;51:1243-1244). Early surgical intervention is recommended for mesial temporal lobe epilepsy (MTLE), the most common and most medically refractory localization-related epilepsy syndrome. If operation is delayed, MTLE has a progressive course, with more severe seizures over time, and associated cognitive and psychosocial disabilities may become irreversible.

Surgery of epilepsy in tuberous sclerosis is evaluated at the Montreal Neurological Institute. (Guerreiro MM, Andermann F, Andermann E et al. Neurology Nov 1998;51:1263-1269). Among 18 patients, 12 having a single tuber or well-localized epileptogenic lesion and treated by lesionectomy or focal resection have the best outcome. Patients without good imaging and EEG correlation respond only partially to corpus callostomy.

Long-term outcome of tuberous sclerosis epilepsy is studied at Okayama University, Japan. (Ohtsuka Y, Ohmori I, Oka E. Epilepsia Nov 1998;39:1158-1163). Twelve (32\%) of 38 patients were seizure-free for $>1$ year at the mean 14 year follow-up (range, 3 to 30 years). Seizures were generalized in 11 , partial and localized in 10 , and they changed from generalized to localizationrelated epilepsies during the clinical course in 17. Neither location nor number of tubers is related to the long-term outcome. Seizure and mental outcomes are least favorable in those with generalized seizures, including West and Lennox-Gastaut syndromes; only $18 \%$ seizure free and $9 \%$ with a normal mentality.

\title{
CLONIDINE-ACTIVATION OF EPILEPTIC FOCI
}

The effects of clonidine, an adrenergic a2 agonist hypotensive agent, and methoxital, a short-acting barbiturate anesthetic, on epileptiform discharges detected by presurgical magnetoencephalography (MEG) were investigated in 14 patients with medically intractable focal epilepsies treated at the University of Erlangen-Nuernberg, Germany. Oral premedication with clonidine increased focal epileptiform discharges in 9 and induced complex partial seizures in 2 patients. Methoxital increased total number of epileptic MEG discharges and the number of spikes contributing to MEG source localizations in 8 patients. Both drugs have proconvulsant effects and may be used as activating agents for localization of epileptogenic foci in EEG, electrocorticography, and MEG. (Kirchberger K, Schmitt H, Hummel C et al. Clonidine- and methoxital-induced epileptiform discharges detected by magnetencephalography (MEG) in patients with localization-related epilepsies. Epilepsia Oct 1998;39:1104-1112). (Reprints: Dr K Kirchberger, Department of Neurology, University of Erlangen-Nuernberg, Schwabachanlage 6, D-91054 Erlangen, Germany).

COMMENT. Clonidine is a second line treatment for children with ADHD, and is especially indicated in those with tics or sleep disorders secondary to methylphenidate. The most frequent side-effect is drowsiness, and an epileptogenic effect in patients has not previously been reported.

Laboratory studies in animals with experimental seizures have demonstrated both anticonvulsant and convulsant effects with clonidine, 
dependent on the dose. Low doses are anticonvulsant while higher doses decrease seizure thresholds. In children receiving clonidine for ADHD, the lowest effective dose should be employed. In those with a history of seizures and/or epileptiform EEG, clonidine should be introduced with caution and in conjunction with an antiepileptic medication.

\section{ANTIEPILEPTIC DRUGS}

\section{VIGABATRIN-INDUCED SEIZURES IN ANGELMAN SYNDROME}

Four children with Angelman syndrome (AS) showed worsening of seizures after introduction of vigabatrin (VGB), at the University Children's Hospital, Zurich, Switzerland. Doses were $50-100 \mathrm{mg} / \mathrm{kg} /$ day in 3 and $150 \mathrm{mg} / \mathrm{kg} / \mathrm{day}$ in 1 . Improved seizure control followed reduction in dose of VGB to $35 \mathrm{mg} / \mathrm{kg} /$ day in one child. Myoclonic, astatic, tonic-clonic, and absence seizures were exacerbated. (Kuenzle Ch, Steinlin M, Wohlrab G, Boltshauser E, Schmitt B. Adverse effects of vigabatrin in Angelman syndrome. Epilepsia Nov 1998;39:1213-1215). (Reprints: Dr Ch Kuenzle, University Children's Hospital, Steinwiesstr 75, CH-8032 Zurich, Switzerland).

COMMENT. This report suggests that vigabatrin is contraindicated in children with Angelman syndrome and epilepsy, irrespective of the seizure type. Previous reports have found myoclonic seizures and atypical absences aggravated, but in the largest series, only $10 \%$ of epilepsies were exacerbated by VGB. Reasons for the unusual adverse effects of VGB in Angelman syndrome are undetermined.

\section{RECTAL DIAZEPAM FOR REPETITIVE SEIZURES}

The effectiveness and safety of a single-dose Diastat (diazepam rectal gel) for treating clusters of acute repetitive seizures in a nonmedical setting by caregivers was evaluated by a multicenter, double-blind study at Oregon Health Sciences University and 28 other centers. Median seizure frequency in children aged 2 years or older was significantly reduced by Diastat compared to placebo, and a greater number of Diastat patients were seizure free post-treatment $(55 \% \mathrm{cf}$ $34 \%$ ). Somnolence was the most common adverse effect. Only 3 of 56 receiving Diastat required additional emergency treatment compared to 7 of 58 in the placebo group. (Cereghino JJ, Mitchell WG, Murphy J, et al, and the North American Diastat Study Group. Treating repetitive seizures with a rectal diazepam formulation. A randomized study. Neurology Nov 1998;51:1274-1282). (Reprints: Dr JJ Cereghino, Oregon Health Sciences University, 3181 SW Sam Jackson Park Road, CDW3, Portland, OR 97201).

COMMENT. A single rectal dose of Diastat administered by a nonprofessional caregiver in a home environment is an effective and safe method of reducing seizure recurrence in children with clusters of acute repetitive seizures. The need for emergency medical treatment is often avoided, and family life is less disruptive. Respiratory depression, a safety concern after IV diazepam, was not observed after rectal Diastat.

\section{GABAPENTIN MONOTHERAPY FOR PARTIAL SEIZURES}

A randomized double-blind trial of gabapentin monotherapy in patients with newly diagnosed partial epilepsy was conducted by an international study group. Gabapentin in 74 patients in each of 3 dosage groups $(300,900$, or 1800 $\mathrm{mg} / \mathrm{day})$ was compared to open-label carbamazepine in 74 patients $(600 \mathrm{mg} / \mathrm{day})$ 